\title{
The Use of Geogebra Software as a Tool to Understand the Concept of Limit at the Under Graduate Level
}

\author{
Arup Kumar Saha ${ }^{1 *}$ and Gauri Roy ${ }^{2}$
}

\author{
${ }^{1}$ Regional Institute of Education (NCERT), Bhubaneswar, Odisha, India \\ ${ }^{2}$ D.M. School, Regional Institute of Education (NCERT), Mysuru \\ Corresponding author: saha.ganit@gmail.com
}

\begin{abstract}
In education, information and communication technologies (ICT) provide a modern learning environment in which students can build their own knowledge. In ICT, there is a lot of space for visualisation and experimentation. The aim of this study was to investigate whether instruction with Geogebra has impact on students' achievements regarding their conceptual and procedural knowledge on the concept of limit. For this research study the investigators adopted a quantitative approach, using a true experimental design with a pretest, post-test control group. It was observed that the suggested exercises aided students at the undergraduate level in grasping the principle of limit.
\end{abstract}

Keywords: CAS, DGE, function, ICT, limit

Innovative mathematics software environments have changed the essence of teaching and learning mathematics in recent years, allowing for interactive exploration of different mathematical concepts using multiple representations that are often difficult to construct or interpret without the use of technology. Computer Algebra Systems (CAS) and Dynamic Geometry Environments (DGE) are two examples of modern educational technologies that are particularly useful for teaching mathematics. GeoGebra, cabri geometry, Derive, Mathematica, and Wolfram Alpha, Maple, MuPAD, MathCAD, and Maxima are all considered valuable and useful resources for teaching and learning mathematics. These programmes have tremendous potential for facilitating an active learning approach by encouraging students to participate in exploration and consolidation of their own information. This leads to improved 
conceptual and geometrical comprehension, as well as a more practical learning approach. They've become popular among students as a way to imagine mathematical structures, concretize their abstract nature, and build connections between algebra and geometry. Mathematics educators cannot disregard the emergence of such mathematical methods and their ability to deal with the majority of undergraduate mathematics learning.

The main purpose of this paper is to provide an overview of GeoGebra software as an ICT tool and its benefits in teaching and learning mathematics. Geogebra has the advantage of combining the properties of both CAS and DGE in a single software package. This programme was tested in the Calculus learning process. The traditional chalk and talk approach has its own set of drawbacks. We assume that by incorporating ICT into mathematics instruction, it can be made even more engaging, imaginative, and exploratory. To back up our argument, we provide a small GeoGebra module on Calculus (function, limit, continuity, and differentiability). The instructor has a major impact on the selection and successful use of available ICT resources for teaching mathematics learning processes. Despite the increased use of multiple representations and technology in mathematics instruction, research has shown that much of calculus in high school and college is rote memorization (Ocal Mehmet Fatih). The definition of limit is the most important and fundamental aspect of calculus. Many researchers believe that many high school students get good grades by concentrating on algorithms and procedures rather than comprehension. The preliminary of calculus, which is often taught from a theoretical viewpoint and does not include a general description of calculus, is a major stumbling block. Students often encounter difficulties and develop coping mechanisms (usually rote memorization of procedures) rather than using intuition when it comes to the definition and processes of calculus, due to variations in the pedagogical method taken at various levels. By concentrating instruction on the creation of key concepts rather than concrete procedures, the use of dynamic software for developing conceptual understanding will help to close this gap. Students' problems with calculus principles are thought to be due to a lack of knowledge of the graphic and algebraic dimensions of those concepts. Many students have trouble visualising the idea of cap. Many students haphazardly resort to procedures without a complete understanding of what to use or why they are using them due to their difficulty reading or visualising complex relations in the fundamental definition of limit. I believe that by using dynamic mathematics software, teachers can help students associate graphic and algebraic representations of the same definition, improving calculus teaching and learning.

\section{Geogebra}

GeoGebra is a Dynamic Mathematics Software (DMS) that may be used to teach and learn mathematics at all levels, from middle school to college. It is as simple to use as Dynamic Geometry Software (DGS), but it also has rudimentary CAS functions to bridge some gaps between geometry, algebra and calculus. GeoGebra is a free and open source software. GeoGebra was intended to assist children in improving their math skills. It promotes mathematical experiments and discoveries both in the classroom and at home, and it can be used for active and problem-oriented instruction. 


\section{Method}

This study took a quantitative approach, using a true experimental design with a pre-test, post-test control group. The effect of Geogebra instruction on students' conceptual, procedural, and overall performance on the concept and application of limit was compared to the effect of education without using technology with this design in this study. This study was conducted in two groups of calculus courses of first semester B.Sc.B.Ed. students at the Regional Institute of Education (NCERT), Bhubaneswar. In one group, there were 17 students, while in the other, there were 16 students. This study was carried out using the convenience sampling method (Tatar, E., \& Zengin, Y., 2016). A group of 17 students was chosen at random to be the experimental group, in which Geogebra aided instruction was used. The other group, consisting of 16 students, was designated as the control group, and their instruction did not include the use of technology. It was expected that they were familiar with the concepts of set, relation, and function. Students were assigned to the Institute based on their performance in the NCERT Higher Secondary Board Examination and Common Entrance Exam. As a result, their exam scores only vary by a modest margin. Furthermore, kids in the same grade level were allocated to either of the groups at random. Furthermore, the results of the class test (internal) ensured that both groups were mathematically equal (Bhagat Kaushal Kumar, 2014).

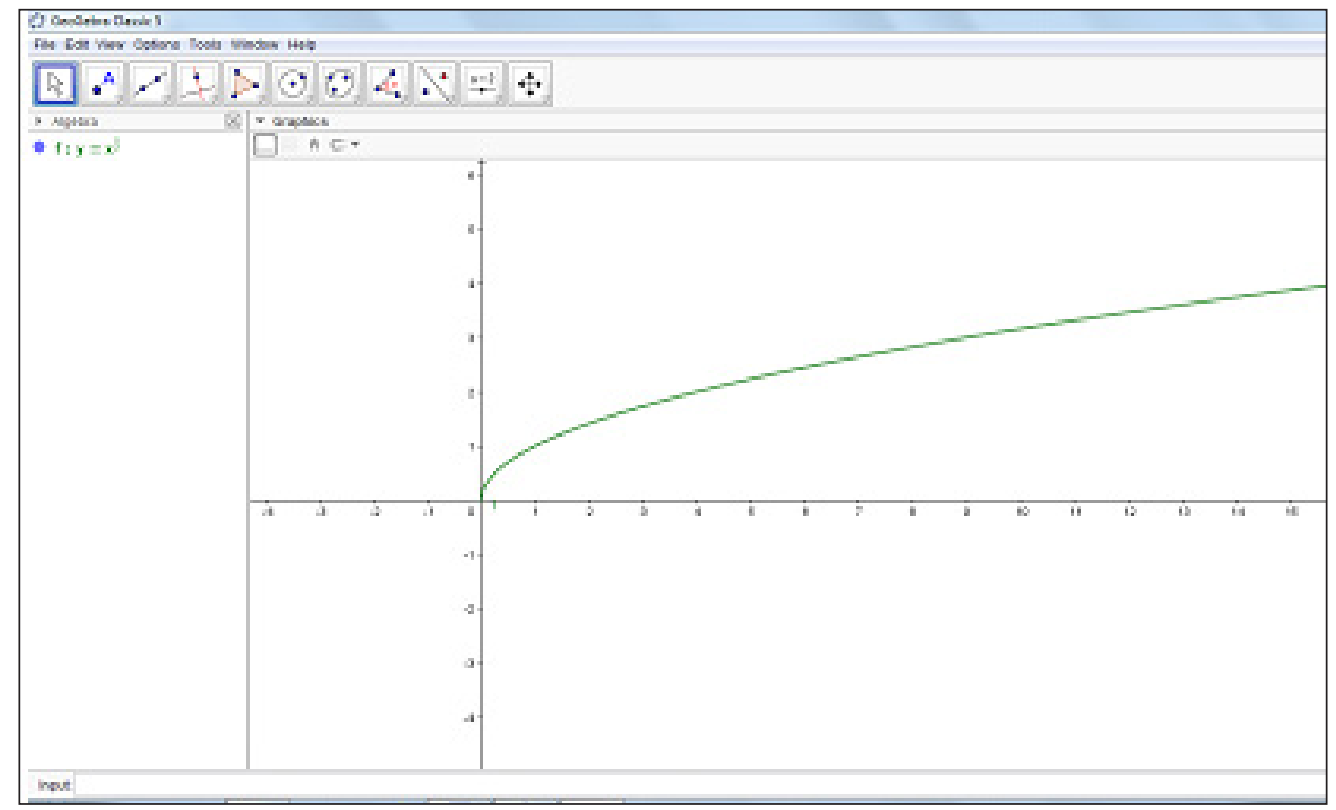

Fig. 1: The material used to explain the domain of definition of a function

The Concept and Application of Limits was the primary data collection method in this study (CAL). It was given as a pre- and post-test to both the control and experimental groups. Ten questions on set theory, relation, and function are included in the pre-test materials. The post-test consists of 10 openended questions, five of which are primarily concerned with procedural knowledge. The remaining five 
questions, on the other hand, were mostly concerned with conceptual understanding. The questions were adapted from several course texts or created by the researchers themselves. Before employing the test as a data collection instrument, a rubric was created that included the exam's purpose, definitions for procedural and conceptual knowledge, and criteria for picking questions that fit the goal. Yank's (2016) definition for conceptual and procedural knowledge was adopted in this study because it fit the goal of the investigation. As previously stated, there are no clear lines separating conceptual and procedural knowledge (Yank, 2016; Tatar, E., \& Zengin, Y., 2017). Students may, however, have more conceptual knowledge of a topic than procedural knowledge, or vice versa. After dividing the sessions into control and experimental groups, each were given 50 minutes of CAL. The calculus lesson lasted three hours each week. In three weeks, the same lecturer presented the topic, which covered the concept and application of limit. In both sessions, he asked the identical question and applied the same techniques. The difference between the sessions during teaching activities was that the instructor used Geogebra to answer the questions and complete the activities. During the instructions, more than ten Geogebra files were used.

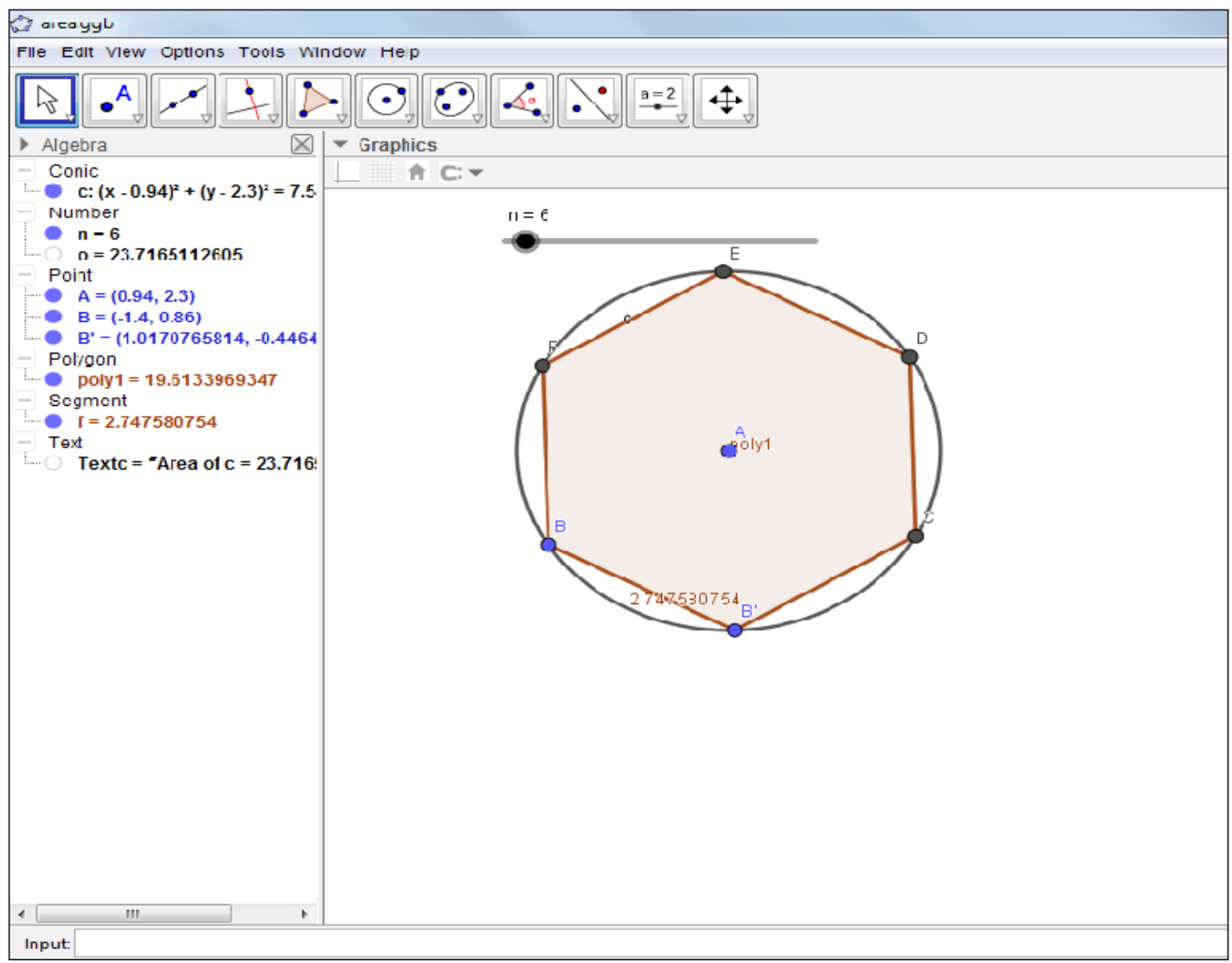

Fig. 2: Model presented to students for basic idea on calculus 


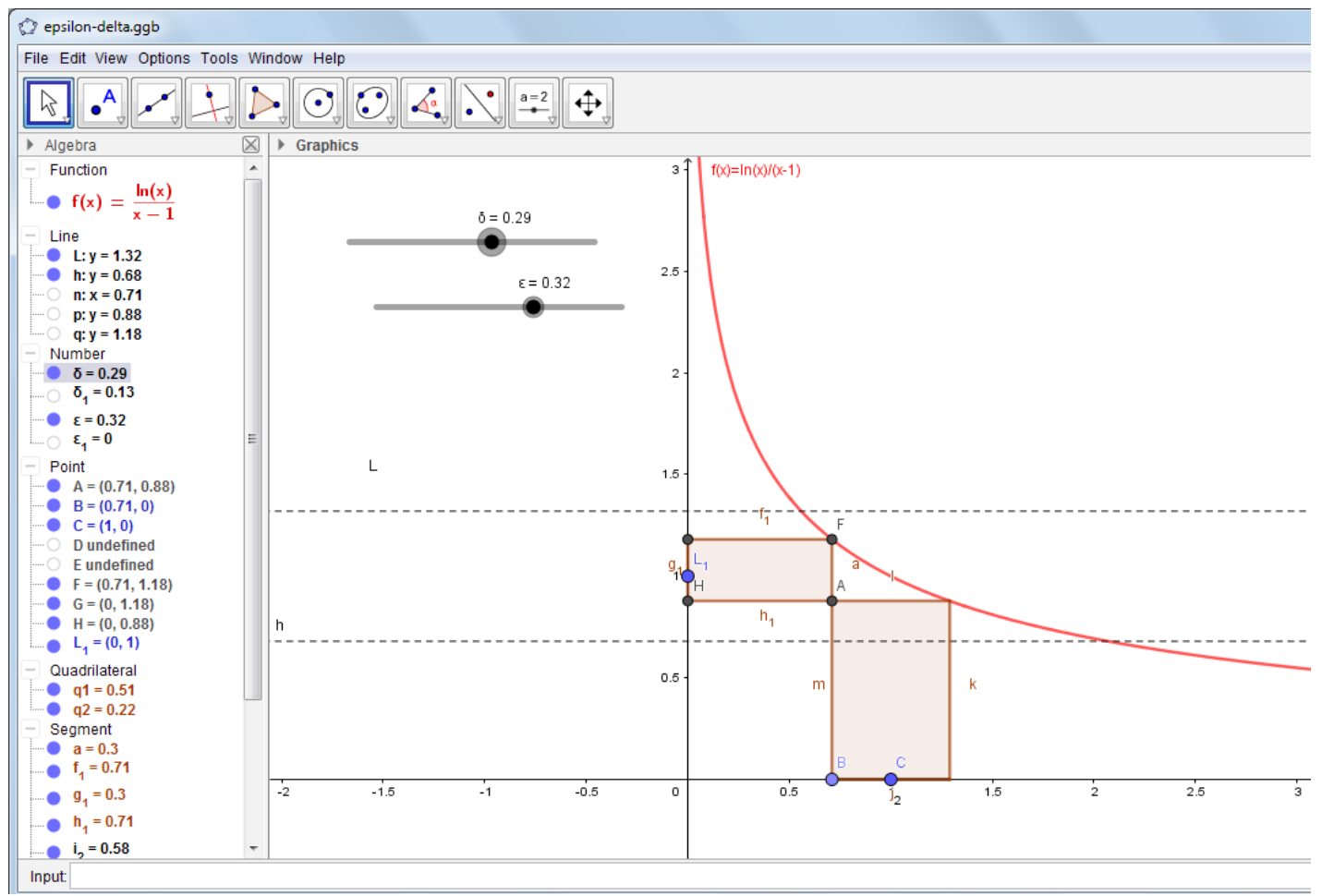

Fig. 3: Model presented to students about definition of limit

In control group's classroom, students followed the instructions in the traditional based method using the standard books of calculus.

Table 1: The summary of the research design

\begin{tabular}{cccc}
\hline Groups & Pre-test & Intervention & Post-test \\
\hline Geogebra & CAL & Teaching with Geogebra & CAL \\
Control & CAL & Teaching without Geogebra & CAL \\
\hline
\end{tabular}

The CAL included of six questions, three of which dealt with conceptual knowledge and the rest with procedural knowledge. The CAL assessment rubric was created by researcher and a teacher with prior calculus teaching expertise.

\section{RESULT}

To ensure that the groups were comparable, the ADT was administered to students in both groups as a pre-test using an independent samples t-test with a significance level $p=.05$. 
Saha and Roy

There was no statistically significant mean difference between the Geogebra group students' scores and the control group students' scores, according to Table 2. These values indicated that the groups were comparable and that the study could be undertaken on them.

In the post-test application of CAL, the same approach was applied to students' scores acquired from conceptual and procedural knowledge questions, as well as their overall scores.

Table 2: Geogebra and control groups students' pre-test scores in CAL were compared using independent samples t-tests

\begin{tabular}{cccccc}
\hline Groups & N & Mean & SD & t-value & Sig \\
\hline Geogebra & 25 & 58.15 & 10.05 & \multirow{2}{*}{0.3102} & 0.7581 \\
\hline Control & 24 & 59.10 & 9.31 & & \\
\hline
\end{tabular}

According to the Table 3 there was a statistically significant difference in the mean scores for students' conceptual knowledge scores from post-tests for the Geogebra group and the control group. This finding revelled that the students who received instruction with Geogebra statistically achieved better scores from the questions investigating students' conceptual knowledge in post-test as compared to control group students who were instructed without Geogebra during teaching processes

Table 3: Post-test scores for procedural knowledge problems in CAL using an independent samples t-test for Geogebra and control groups students

\begin{tabular}{cccccc}
\hline Groups & N & Mean & SD & t-value & Sig. \\
\hline Geogebra & 25 & 8.15 & 3.94 & \multirow{2}{*}{1.12} & .292 \\
\hline Control & 24 & 7.68 & 2.75 & & \\
\hline
\end{tabular}

According to Table 4, the mean difference in post-test results for the procedural knowledge items between the Geogebra and control groups students was just 1.19. This result demonstrated that Geogebra education had no statistically significant impact on students' procedural knowledge while learning the idea and applications of limit compared to training without Geogebra.

Table 4: Geogebra and control groups students' overall post-test scores in CAL using Independent Samples t-tests

\begin{tabular}{cccccc}
\hline Groups & N & Mean & SD & t-value & Sig. \\
\hline Geogebra & 25 & 14.98 & 4.78 & \multirow{2}{*}{2.23} & .043 \\
\hline Control & 24 & 11.83 & 4.55 & & \\
\hline
\end{tabular}

In the post-test, a similar analysis was performed on the students' overall scores. The findings of the independent samples t-test revealed a statistically significant mean difference between the Geogebra and control groups' overall scores. As a result, pupils in the Geogebra group scored much higher on the CAL post-test than those who were not taught with it. This resulted in the interpretation of that instruction using Geogebra being a considerably better way to teach the concept and applications of limit than without it. 


\section{DISCUSSION AND CONCLUSION}

The influence of 'Geogebra' in teaching and learning mathematics ideas at the undergraduate level was investigated using a quasi-experimental research methodology. The outcomes of this study revealed three primary conclusions when comparing the achievements of experimental and control group students in terms of conceptual and procedural knowledge, as well as overall scores on concept and applications of limit subject. Although the mean scores of the groups did not differ substantially for the questions probing their procedural knowledge, the mean scores of the groups differed significantly for the questions probing their conceptual knowledge and for their overall scores in the CAL post-test.

\section{REFERENCES}

1. Albano, G. and Desiderio, M. 2002. Improvements in teaching and learning using CAS, Proceedings of the Vienna International Symposium on Integrating Technology into Mathematics Education, Vienna, Austria.

2. Bhagat Kaushal Kumar and Chang Chum-Yen. 2014. Visualizing Projectile Motion Using a Dynamic Mathematical Software: Geogebra, Proceedings of the International Science Education Conference 2014, National Institute of Education, Singapore.

3. De Tilak 2000. Projectile motion with mathematica, International Journal of Mathematical Education in Science and Technology, 31(5): 749-755.

4. Ocal Mehmet Fatih. 2017. The Effect of Geogebra on Students' Conceptual and Procedural Knowledge: The Case of Application of Derivative, Higher Education Studies, 7(2).

5. Yanık, H.B. 2016. Kavramsal ve işlemsel anlama. In: E. Bingölbali, S. Arslan, \& Zembat, İ. Ö. (Eds.), Matematik eğitiminde teoriler (pp. 101-116). Ankara, Turkey: Pegem Akademi.

6. Zengin, Y. and Tatar, E. 2014. The teaching of polar coordinates with dynamic mathematics software. International Journal of Mathematical Education in Science and Technology, 46(1): 127-139. 
